\title{
Is surgical resection indicated for a solitary non-small cell lung cancer recurrence?
}

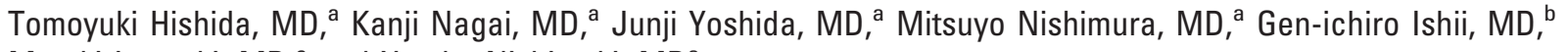
Motoki Iwasaki, MD, ${ }^{\mathrm{c}}$ and Yutaka Nishiwaki, MD ${ }^{\mathrm{a}}$

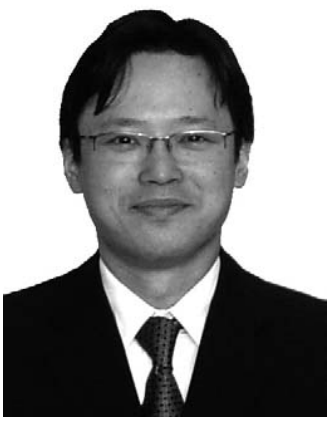

Dr T. Hishida

Objectives: Some investigators have reported long-term survival after surgical resection of a solitary non-small cell lung cancer recurrence in various sites. However, the role and indications of the second operation remain unclear.

Methods: We reviewed 28 patients with a solitary recurrence after successful initial resection of primary non-small cell lung cancer who underwent resection of the recurrent lesion. The clinicopathologic factors associated with outcome were analyzed.

Results: There were 17 men and 11 women. Recurrence resection was performed for the following sites: 16 in the lung, 5 in the brain, 2 in the adrenal gland, and 1 each in the chest wall, stomach, skin, pelvic lymph node, and malar bone. The median survival time was 25 months, and the 1-, 2-, and 5-year survival rates after recurrence were $89 \%, 59 \%$, and 32\%, respectively. Advanced p-stage (p-stage II and III, $\mathrm{n}=14$ ) of the primary tumor was the significant negative prognostic factor. Patients with p-stage II or III had survival equivalent to that of those who had multiple recurrences or were unfit for further surgical intervention.

Conclusions: Resection of a solitary non-small cell lung cancer recurrence might provide long-term survival in highly selected patients. However, surgical resection might be contraindicated if the primary tumor is stage II or III.

From the Department of Thoracic Oncology, National Cancer Center Hospital East, ${ }^{\text {a }}$ Chiba, Japan; the Pathology Division, National Cancer Center Research Institute East, ${ }^{\mathrm{b}}$ Chiba, Japan; and the Epidemiology and Prevention Division, Research Center for Cancer Prevention and Screening, National Cancer Center, ${ }^{\mathrm{c}}$ Tokyo, Japan.

The work was supported in part by a Grantin-Aid for Cancer Research from the Ministry of Health, Labour and Welfare in Japan.

Received for publication Sept 8, 2005; revisions received Nov 20, 2005; accepted for publication Nov 28, 2005.

Address for reprints: Tomoyuki Hishida, MD, Department of Thoracic Oncology, National Cancer Center Hospital East, 6-5-1, Kashiwanoha, Kashiwa, Chiba, 277-8577 Japan (E-mail: thishida@nifty.com).

J Thorac Cardiovasc Surg 2006;131:838-42 $0022-5223 / \$ 32.00$

Copyright (๑) 2006 by The American Association for Thoracic Surgery

doi:10.1016/j.jtcvs.2005.11.028
$\mathrm{F}$ Tive-year survival rates of patients with non-small cell lung cancer (NSCLC) have been disappointing, even after successful complete resection, with about $50 \%$ of patients eventually experiencing recurrence and death from the disease. ${ }^{1}$ Recurrent lesions are generally multiple and disseminated, and additional surgical intervention is usually not indicated. Some investigators have reported long-term survivals after solitary recurrence resection of the brain, adrenal gland, spleen, liver, and bone. ${ }^{2-10}$ However, the role and indication of surgical intervention remain unclear. The aim of this study is to investigate clinicopathologic characteristics of patients with NSCLC who underwent resection of a solitary recurrent lesion and to identify prognostic factors.

\section{Patients and Methods}

\section{Patients}

We retrospectively reviewed the clinical and pathologic files of 1698 consecutive patients with NSCLC who had undergone complete surgical resection at the National Cancer Center Hospital East from 1989 through 2002. Data collection and analyses were approved, and the need for obtaining informed consent from each patient was waived by the institutional review board in January 2004. Patients with synchronous metastasis (M1) were excluded. Among them, we identified $592(35 \%)$ patients with locoregional or distant recurrence in 2003 or earlier. We excluded patients with second pulmonary lesions that were not clearly distinguished from metachronous second primary NSCLC on the basis of the criteria of Martini and Melamed. ${ }^{11}$ Our follow-up procedures included physical examination, chest roentgenogra- 


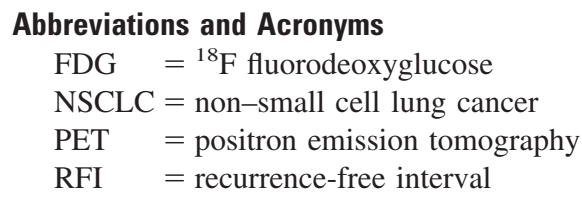

phy, and blood testing, including tumor markers, 1 month after the initial operation, every 3 to 6 months during the first 3 years, and every half year to 1 year thereafter. If any abnormality was found, we performed computed tomographic scans. We did not routinely perform bone scanning and brain examinations for asymptomatic patients. When a lesion suggesting locoregional or distant recurrence was detected, we scrutinized the whole body radiologically.

Thirty of the 592 patients underwent resection of a solitary recurrent lesion. Among them, 2 patients who had recurrence-free intervals (RFIs) of 1 and 4 months, respectively, were eliminated from this study because they possibly had undetectable "missed" M1 disease at the initial operation. Nine of the 28 patients were symptomatic at the time of recurrence detection. All but 1 patient, who had intrapulmonary recurrence, were asymptomatic. The median period from recurrence detection to the second operation was 2.6 months (range, 0.2-24 months). The follow-up protocols were the same before and after recurrence resection. The median follow-up period after recurrence resection was 33 months, ranging from 11 to 128 months.

For the remaining 562 patients, surgical intervention was not indicated because recurrences were multiple, patients were unfit for further surgical intervention, or both. They underwent palliative chemotherapy, radiotherapy, or best supportive care. Patients with multiple recurrences who underwent palliative operations for symptomatic sites were included in this group.

\section{Prognostic Evaluation}

We attempted to identify prognostic factors associated with subsequent survival after resection of a solitary recurrent lesion. We evaluated the following factors: clinical characteristics at recurrence (sex, age, carcinoembryonic antigen level, time from initial resection to recurrence detection [RFI], symptoms at the time of recurrence, site of recurrence, and mode of recurrence [locoregional or distant]) and pathologic findings of the primary lung cancer (histology, tumor size, lymph node status, p-stage, and lymphatic and vascular permeations). We defined locoregional recurrence as recurrence within the ipsilateral thorax and distant recurrence as all other recurrences. Each pathologic specimen was reviewed by a board-certified pathologist who was blinded to the clinical outcome. Histology was specified on the basis of the World Health Organization classification for cell types. ${ }^{12}$ Pathologic stages were determined on the basis of the TNM classification of the International Union Against Cancer. ${ }^{13}$

\section{Survival Analysis}

Survivals were calculated by using the Kaplan-Meier method and were compared with the log-rank test. Zero time was the date of recurrence identification, and the terminal event was defined as death from any cause. An observation was censored at the last
TABLE 1. Clinicopathologic characteristics of 28 patients with NSCLC who underwent resection of a solitary recurrent lesion

\begin{tabular}{|c|c|c|}
\hline Characteristics & Value & No. \\
\hline \multicolumn{3}{|l|}{$\begin{array}{l}\text { Clinical characteristics at } \\
\text { recurrence }\end{array}$} \\
\hline \multirow{2}{*}{$\begin{array}{l}\text { Age at recurrence } \\
\text { resection (y) }\end{array}$} & Median & 65 \\
\hline & Range & $39-73$ \\
\hline \multirow[t]{2}{*}{ Sex } & Male & 17 \\
\hline & Female & 11 \\
\hline \multirow[t]{2}{*}{$\mathrm{RFI}(\mathrm{mo})$} & Median & 23 \\
\hline & Range & $6-82$ \\
\hline \multirow[t]{2}{*}{ CEA level (ng/mL) } & Median & 3.5 \\
\hline & Range & $0.5-3286$ \\
\hline \multirow[t]{9}{*}{ Recurrent site } & Ipsilateral lung & 8 \\
\hline & Contralateral lung & 8 \\
\hline & Brain & 5 \\
\hline & Adrenal grand & 2 \\
\hline & Chest wall & 1 \\
\hline & Stomach & 1 \\
\hline & Skin & 1 \\
\hline & Abdominal lymph node & 1 \\
\hline & Bone (malar bone) & 1 \\
\hline \multicolumn{3}{|l|}{$\begin{array}{l}\text { Pathologic characteristics of } \\
\text { primary tumor }\end{array}$} \\
\hline \multirow[t]{4}{*}{ Histology } & Adenocarcinoma & 21 \\
\hline & $\begin{array}{l}\text { Squamous cell } \\
\text { carcinoma }\end{array}$ & 5 \\
\hline & $\begin{array}{l}\text { Adenosquamous } \\
\text { carcinoma }\end{array}$ & 1 \\
\hline & Pleomorphic carcinoma & 1 \\
\hline Size of primary tumor $(\mathrm{cm})$ & Mean $\pm S D$ & $4.1 \pm 1.7$ \\
\hline \multirow[t]{3}{*}{$\mathrm{p}$-Stage of primary tumor } & $\mathrm{IA} / \mathrm{IB}$ & $4 / 10$ \\
\hline & IIA/IIB & $2 / 6$ \\
\hline & IIIA/IIIB & $4 / 2$ \\
\hline $\begin{array}{l}\text { Nodal status of primary } \\
\text { tumor }\end{array}$ & N0/N1/N2 & $18 / 7 / 3$ \\
\hline
\end{tabular}

$R F I$, Recurrence-free interval; $C E A$, carcinoembryonic antigen; $S D$, standard deviation.

follow-up when the patient was alive or lost to follow-up. Factors with a $P$ value of less than .15 were entered into the multivariate analysis by using the Cox proportional hazards stepwise model. All statistical analyses were performed with a software package (JMP, release 5.0; SAS Institute Inc, Cary, NC).

\section{Results}

\section{Patient Characteristics}

Clinicopathologic characteristics of 28 patients who underwent resection of a solitary recurrent lesion are shown in Table 1 . There were 17 men and 11 women, with a median age of 65 years (range, 39-73 years) at the time of resection of the recurrent lesion. At the initial operation, 26 of 28 patients underwent lobectomy and systemic mediastinal lymph node dissection. Two patients underwent limited 


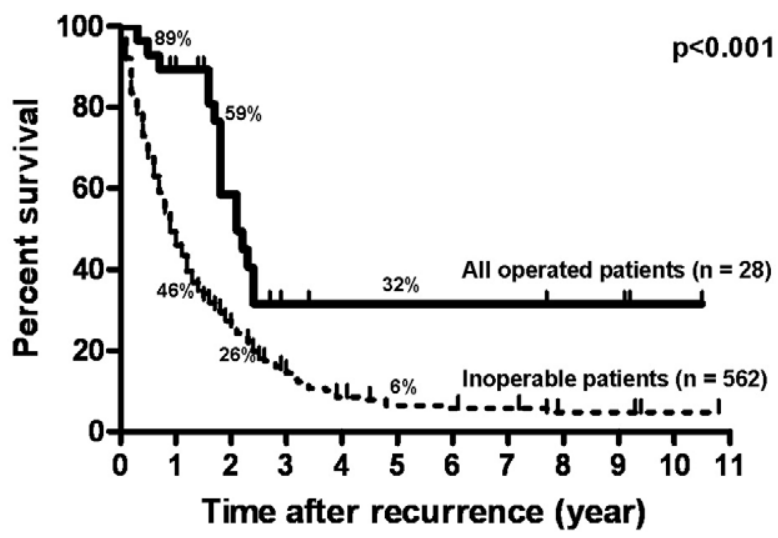

Patients at risk

$\begin{array}{llll}\begin{array}{l}\text { All operated } \\ \text { patients }\end{array} & 28 & 24 & 13 \\ \begin{array}{l}\text { Inoperable } \\ \text { patients }\end{array} & 365 & 154 & 63\end{array}$

Figure 1. Comparative survival curves among 28 resected patients and 562 patients without resection. The difference in survival probability after recurrence is significant $(1-, 2-$, and 5 -year survivals after recurrence: $89 \%, 59 \%$, and $32 \%$ vs $46 \%, 26 \%$, and 6\%; $P<.001$ ).

lung resection because of insufficient pulmonary reserve. Neoadjuvant platinum-based chemotherapy was administered to 1 patient because of clinical N2 status. All patients achieved macroscopically complete surgical removal of their primary NSCLC tumor, but the resection margin was pathologically positive in 1 patient. The patient had recurrence in the adrenal gland. RFI was almost 2 years (median, 23 months; range, 6-82 months). The lung $(\mathrm{n}=16)$ was the most frequent site of recurrence. The mode of resection for intrapulmonary recurrences included 3 completion pneumonectomies, 1 lobectomy, and 12 limited resections. Distal gastrectomy was performed for the patient who had gastric recurrence with severe progressive anemia, and open lymph node resection was performed for the patient with pelvic lymph node recurrence. Complete removal of the recurrence was accomplished in all patients. There was no complication after resection of the recurrent lesion. One of 5 patients with brain recurrence received whole-brain irradiation postoperatively. No patients underwent systemic chemotherapy after resection of the recurrent lesion.

Survival and Prognostic Factors After Resection of the Solitary Recurrent Lesion

Figure 1 shows comparative survival curves after recurrence among 28 patients who underwent resection of the solitary recurrent lesion and 562 patients in whom an additional operation was not indicated. Overall 1-, 2-, and 5-year survivals after recurrence were significantly better in pa- tients who underwent resection of a solitary recurrent lesion than in those who did not undergo resection $(89 \%, 59 \%$, and $32 \%$ vs $46 \%, 26 \%$, and $6 \% ; P<.001$ ). The median survival times after recurrence were 25 and 11 months, respectively.

Table 2 shows the relationship between survival after resection of the recurrent lesion and the clinicopathologic characteristics of the 28 patients. Multivariate analysis demonstrated that advanced p-stage (stage II-III) of the primary lung cancer was the significant negative prognostic factor associated with survival after recurrence detection (hazard ratio, 6.15; 95\% confidential interval, 1.09-30.8; $P=.04$ ). As shown in Figure 2, the patients with p-stage II or III disease demonstrated survival statistically equivalent to that of patients not undergoing resection after recurrence detection $(P=.11)$. In 14 patients with p-stage I disease, 10 and 3 patients survived for more than 2 and 5 years, respectively, after recurrence detection. One with recurrence in the malar bone is surviving for 7 years without a distant failure. In contrast, 3 and 1 of 14 patients with p-stage II or III disease survived for more than 2 and 5 years, respectively, but with a distant failure.

\section{Discussion}

Most recurrences after primary NSCLC resection are multiple and disseminated and are usually treated with systemic chemotherapy when patients can tolerate it. Although many studies have shown that systemic chemotherapy prolongs survival in unresectable stage IV NSCLC, there have been no large-scale, randomized prospective trials addressing whether chemotherapy improves survival of patients with recurrence. ${ }^{14}$ In an effort to improve long-term tumor control and subsequent survival, attempts have been made to incorporate surgical intervention in selected cases of solitary NSCLC recurrence. Evidence that a solitary recurrent lesion can be effectively treated with surgical intervention exists for malignancies other than lung cancer. For colorectal cancer, melanoma, and thyroid cancer, resection of recurrent lesions can offer prolonged survival. ${ }^{15-17}$ For lung cancer, some investigators have reported acceptable survival after resection of the recurrent lesion, but others have contradicted these conclusions. Abrahams and coworkers ${ }^{4}$ demonstrated a satisfactory outcome in brain recurrence, with a median survival time of 18 months and a 5-year survival rate of $28.9 \%$. In contrast, Saitoh and associates ${ }^{2}$ conducted 24 brain resections, with a 5-year survival rate of only $8.3 \%$. Prognostic factors for survival after resection of the recurrent lesion have not been clarified.

Although our patient population was heterogeneous, with a variety of recurrence sites, the overall survival after resection of the recurrent lesion was acceptable by current standards, with a median survival time of 25 months and a 5 -year survival rate of $32 \%$. The patients with a solitary NSCLC recurrence arising from an advanced primary tumor 
TABLE 2. Relationship between patient clinicopathologic characteristics and survival after resection of a solitary recurrent lesion

\begin{tabular}{|c|c|c|c|c|c|c|c|}
\hline & Factors & No. & $\begin{array}{l}\text { MST } \\
\text { (mo) }\end{array}$ & 2-y survival (\%) & 5-y survival (\%) & $\begin{array}{c}\text { Univariate } \\
\text { analysis, } \\
\boldsymbol{P} \text { value }\end{array}$ & $\begin{array}{c}\text { Multivariate } \\
\text { analysis, } \\
P \text { value }\end{array}$ \\
\hline \multirow[t]{2}{*}{ Age at recurrence resection (y) } & $\geq 65$ & 14 & 22 & 43 & 26 & .41 & - \\
\hline & $<65$ & 14 & 27 & 75 & 38 & & \\
\hline \multirow[t]{2}{*}{ Sex } & Male & 17 & 26 & 53 & 31 & .48 & - \\
\hline & Female & 11 & 28 & 67 & 33 & & \\
\hline \multirow{2}{*}{$\mathrm{RFI}(\mathrm{y})$} & $\geq 2$ & 13 & 26 & 68 & 45 & .25 & - \\
\hline & $<2$ & 15 & 27 & 51 & 22 & & \\
\hline \multirow[t]{2}{*}{ CEA level at recurrence $(\mathrm{ng} / \mathrm{mL})$} & $>5$ & 9 & 22 & 30 & Not reached & .13 & .80 \\
\hline & $\leq 5$ & 19 & 30 & 70 & 38 & & \\
\hline \multirow{2}{*}{ Symptoms at recurrence } & + & 9 & 26 & 53 & 18 & .33 & - \\
\hline & - & 19 & 28 & 60 & 36 & & \\
\hline \multirow[t]{2}{*}{ Site of recurrence } & Intrapulmonary & 16 & 30 & 71 & 40 & .15 & .50 \\
\hline & Extrapulmonary & 12 & 22 & 42 & 21 & & \\
\hline \multirow[t]{2}{*}{ Mode of recurrence } & Locoregional & 10 & 26 & 57 & 46 & .41 & - \\
\hline & Distant & 18 & 27 & 61 & 23 & & \\
\hline \multirow[t]{2}{*}{ Histology } & $\mathrm{Ad}$ & 21 & 26 & 55 & 31 & .73 & - \\
\hline & Non-Ad & 7 & 30 & 67 & 33 & & \\
\hline \multirow[t]{2}{*}{ Size of primary tumor $(\mathrm{cm})$} & $\geq 4$ & 14 & 26 & 51 & 17 & .18 & - \\
\hline & $<4$ & 14 & 28 & 66 & 47 & & \\
\hline \multirow[t]{2}{*}{ Nodal status of primary tumor } & No $(\mathrm{N}-)$ & 18 & 30 & 67 & 40 & .08 & .40 \\
\hline & $\mathrm{N} 1 / \mathrm{N} 2(\mathrm{~N}+)$ & 10 & 22 & 41 & 14 & & \\
\hline \multirow[t]{2}{*}{$\mathrm{p}$-Stage of primary tumor } & I & 14 & - & 76 & 51 & .0045 & .04 \\
\hline & $\| / I I$ & 14 & 19 & 10 & 10 & & \\
\hline \multirow[t]{2}{*}{ Ly in primary tumor } & + & 10 & 21 & 44 & Not reached & .32 & - \\
\hline & - & 18 & 27 & 67 & 33 & & \\
\hline \multirow[t]{2}{*}{$V$ in primary tumor } & + & 17 & 27 & 57 & 29 & .97 & - \\
\hline & - & 11 & 26 & 61 & 36 & & \\
\hline
\end{tabular}

MST, Median survival time; $R F I$, recurrence-free interval; $C E A$, carcinoembryonic antigen; $A d$, adenocarcinoma; $L y$, lymphatic permeation; $V$, vascular permeation.

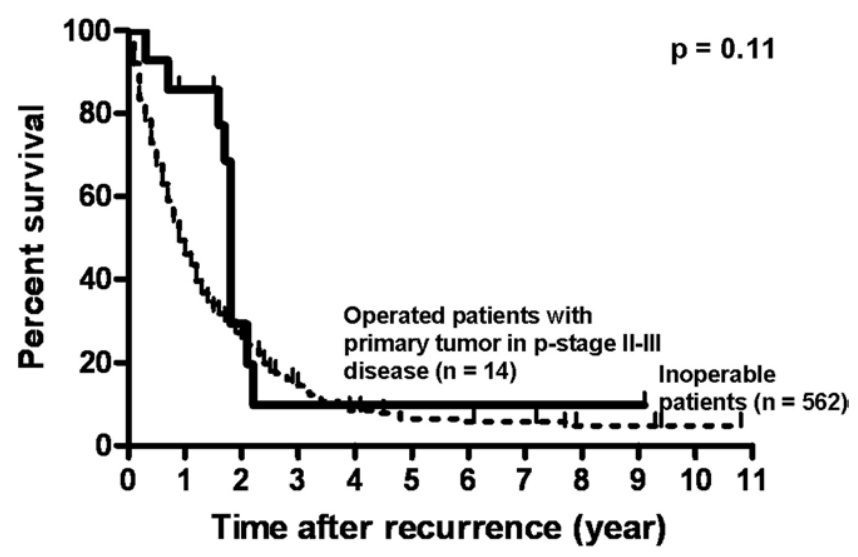

Figure 2. Comparative survival curves among 14 resected patients with p-stage II or III primary non-small cell lung cancer and $\mathbf{5 6 2}$ patients without resection. There is no significant difference in survival probability after recurrence $(P=.11)$. with p-stage II or III disease, however, had a poor outcome equivalent to that seen in patients with recurrent NSCLC in whom surgical intervention was not indicated. This suggests that advanced stage (ie, II or III) in the primary tumor is a contraindication for surgical intervention in patients with a solitary recurrence. Consistent with our result, Yoshino and coworkers ${ }^{18}$ described a strong relationship between pathologic stage and clinical courses after recurrence in patients with NSCLC. They reported that the mean postrecurrent survival time was 590 days in pathologic stage I disease, 381 days in stage II disease, 257 days in stage IIIA disease, and 180 days in stage IIIB disease, with a significant difference being observed between stages I and IIIA ( $P=$ .0215). In patients with advanced and biologically aggressive NSCLC, a solitary recurrence might be just the beginning of progressive-disseminated disease.

In our series patients who underwent resection of the intrapulmonary recurrent lesion showed slightly but not significantly better survival than the extrapulmonary recurrence group $(P=.15)$. This might be because some in- 
trapulmonary lesions were actually metachronous second primary lung cancers. We can expect better prognosis for metachronous lung cancer compared with intrapulmonary recurrence. ${ }^{19,20}$ It can often be hard to discriminate a solitary pulmonary recurrence from a metachronous second primary lung cancer if the 2 lesions are of the same histologic type. ${ }^{21}$ Therefore aggressive surgical resection for an intrapulmonary lesion might be justified for patients with adequate pulmonary reserve, regardless of the primary tumor pathology.

Although we did not perform positron emission tomography (PET) with ${ }^{18} \mathrm{~F}$ fluorodeoxyglucose (FDG) for the patients in this study, FDG-PET has been reported to be a helpful adjunct in screening for distant metastases but not for brain metastases. ${ }^{22}$ Several investigators have reported that FDG-PET could detect unexpected metastatic lesions in $10 \%$ to $20 \%$ of patients with newly diagnosed NSCLC. ${ }^{23,24}$ PET imaging might also be helpful in avoiding surgical intervention in patients who have multiple recurrent lesions. ${ }^{25}$ However, it is well known that FDG is not tumor specific and is also taken up in benign lseions. ${ }^{22}$ Lardinois and colleagues ${ }^{26}$ have reported that $46 \%$ of solitary extrapulmonary lesions detected by means of integrated PET and computed tomography were unrelated to lung cancer metastases. Further studies will be needed to clarify whether PET imaging is useful in identifying more clearly the population that benefits from additional surgical intervention and in prolonging subsequent survival.

The limitation of the current study is that the number of enrolled patients, especially in the surgical resection group, was obviously small. Therefore a multi-institutional study would be required to confirm our findings.

In conclusion, long-term survival can be achieved by means of resection of a solitary recurrent lesion in highly selected patients. However, surgical resection might be contraindicated if the primary NSCLC stage is II or III, especially when the recurrent lesion is extrapulmonary.

We thank Professor J. Patrick Barron, International Medical Communications Center, Tokyo Medical University, for reviewing the English-language manuscript.

\section{References}

1. Pisters KM, Le Chevalier T. Adjuvant chemotherapy in completely resected non-small-cell lung cancer. J Clin Oncol. 2005;23:3270-8.

2. Saitoh Y, Fujisawa T, Shiba M, Yoshida S, Sekine Y, Baba M, et al. Prognostic factors in surgical treatment of solitary brain metastasis after resection of non-small-cell lung cancer. Lung Cancer. 1999;24: 99-106.

3. Granone P, Margaritora S, D'Andrilli A, Cesario A, Kawamukai K, Meacci E. Non-small cell lung cancer with single brain metastasis: the role of surgical treatment. Eur J Cardiothorac Surg. 2001;20:361-6.

4. Abrahams JM, Torchia M, Putt M, Kaiser LR, Judy KD. Risk factors affecting survival after brain metastases from non-small cell lung carcinoma: a follow-up study of 70 patients. $J$ Neurosurg. 2001;95:595-600.

5. Porte H, Siat J, Guibert B, Lepimpec-Barthes F, Jancovici R, Bernard A, et al. Resection of adrenal metastases from non-small cell lung cancer: a multicenter study. Ann Thorac Surg. 2001;71:981-5.

6. Luketich JD, Martini N, Ginsberg RJ, Rigberg D, Burt ME. Successful treatment of solitary extracranial metastases from non-small cell lung cancer. Ann Thorac Surg. 1995;60:1609-11.

7. Macheers SK, Mansour KA. Management of isolated splenic metastases from carcinoma of the lung: a case report and review of the literature. Am Surg. 1992;58:683-5.

8. Schmidt BJ, Smith SL. Isolated splenic metastasis from primary lung adenocarcinoma. South Med J. 2004;97:298-300.

9. Nagashima A, Abe Y, Yamada S, Nakagawa M, Yoshimatsu T. Long-term survival after surgical resection of liver metastasis from lung cancer. Jpn J Thorac Cardiovasc Surg. 2004;52:311-3.

10. Shimizu K, Nagai K, Yoshida J, Nishimura M, Hayashi R, Yokose T. Successful management of solitary malar metastasis from lung cancer. Lung Cancer. 2002;36:337-9.

11. Martini N, Melamed MR. Multiple primary lung cancers. $J$ Thorac Cardiovasc Surg. 1975;70:606-12.

12. Travis WD, Colby TV, Corrin B, Shimosato Y, Brambilla E. Histological typing of lung and pleural tumors. 3rd ed. Berlin: Springer Verlag; 1999.

13. International Union Against Cancer. TNM classification of malignant tumors. 5th ed. New York: Wiley-Liss; 1997.

14. Non-small Cell Lung Cancer Collaborative Group. Chemotherapy in non-small cell lung cancer: a meta-analysis using updated data on individual patients from 52 randomised clinical trials. BMJ. 1995;311: 899-909.

15. Fong Y, Salo J. Surgical therapy of hepatic colorectal metastasis. Semin Oncol. 1999;26:514-23.

16. Essner R. Surgical treatment of malignant melanoma. Surg Clin North Am. 2003;83:109-56.

17. Stojadinovic A, Shoup M, Ghossein RA, Nissan A, Brennan MF, Shah JP, et al. The role of operations for distantly metastatic welldifferentiated thyroid carcinoma. Surgery. 2002;131:636-43.

18. Yoshino I, Yohena T, Kitajima M, Ushijima C, Nishioka K, Ichinose Y, et al. Survival of non-small cell lung cancer patients with postoperative recurrence at distant organs. Ann Thorac Cardiovasc Surg. 2001;7:204-9.

19. Pass HI, Carbone DP, Johnson DH, Minna JD. Lung cancer: principles and practice. 3rd ed. Philadelphia: Lippincott Williams and Wilkins; 2004.

20. Rice D, Kim HW, Sabichi A, Lippman S, Lee JJ, Williams B, et al. The risk of second primary tumors after resection of stage I nonsmall cell lung cancer. Ann Thorac Surg. 2003;76:1001-8.

21. Battafarano RJ, Force SD, Meyers BF, Bell J, Guthrie TJ, Cooper JD, et al. Benefits of resection for metachronous lung cancer. $J$ Thorac Cardiovasc Surg. 2004;127:836-42.

22. Pieterman RM, van Putten JW, Meuzelaar JJ, Mooyaart EL, Vaalburg W, Koeter GH, et al. Preoperative staging of non-small-cell lung cancer with positron-emission tomography. N Engl J Med. 2000;343: 254-61

23. Marom EM, McAdams HP, Erasmus JJ, Goodman PC, Culhane DK, Coleman RE, et al. Staging non-small cell lung cancer with wholebody PET. Radiology. 1999;212:803-9.

24. Kalff V, Hicks RJ, MacManus MP, Binns DS, McKenzie AF, Ware $\mathrm{RE}$, et al. Clinical impact of (18)F fluorodeoxyglucose positron emission tomography in patients with non-small-cell lung cancer: a prospective study. J Clin Oncol. 2001;19:111-8.

25. Hellwig D, Groschel A, Graeter TP, Hellwig AP, Nestle U, Schafers $\mathrm{HJ}$, et al. Diagnostic performance and prognostic impact of FDG-PET in suspected recurrence of surgically treated non-small cell lung cancer. Eur J Nucl Med Mol Imaging. Epub September 9, 2005.

26. Lardinois D, Weder W, Roudas M, von Schulthess GK, Tutic M, Moch H, et al. Etiology of solitary extrapulmonary positron emission tomography and computed tomography findings in patients with lung cancer. J Clin Oncol. 2005;23:6846-53. 